\title{
Michel Foucault e a obediência da carne Cristã
}

\author{
Michel Foucault and the obedience of the Christian flesh
}

Agustín Colombo

\section{Resumo}

Este artigo investiga a dimensão política do que Michel Foucault chama a "experiência da Carne", baseando-se na obra maior póstuma do filósofo francês História da sexualidade 4, As confissões da carne (Les Aveux de la chair). Para isso, o artigo se concentra na pesquisa de Foucault sobre o relato cristão da obediência. Em particular, o artigo analisa a íntima interação conceitual entre obediência e vontade na investigação de Foucault sobre João Cassiano e Santo Agostinho. A primeira parte do artigo aborda o principal diagnóstico de Foucault sobre o relato da obediência de Cassiano. Segundo este relato, na vida monástica, a obediência perfeita requer que os indivíduos renunciem à sua própria vontade. A segunda parte do artigo tem seu foco na análise de Foucault da teoria da libido de Santo Agostinho. Para Agostinho, a condição de obediência, em particular a obediência às regras sexuais, depende do bom uso que os indivíduos fazem da sua própria vontade. As conclusões do artigo destacam o papel crucial da interação entre obediência e vontade, de modo a possibilitar compreender a forma de governamentalidade construída pela experiência cristã da carne.

Palavras-chave : Michel Foucault. As confissões da carne. Carne. Obediencia. Vontade.

a Boston College, Boston, Massachusetts, USA. PhD, e-mail: acolombo@mailfence.com 
This article investigates the political dimension of what Michel Foucault calls the "experience of the Flesh" based on French philosopher's posthumous major work History of Sexuality volume 4, The Confessions of the Flesh (Les Aveux de la chair). In order to do so, the chapter focuses on Foucault's research on the Christian account of obedience. In particular, the article analyzes the intimate conceptual interplay between obedience and will in Foucault's investigation on John Cassian and Saint Augustine. The first part of the article addresses Foucault's main diagnosis of Cassian's account of obedience, according to which, in monastic life, perfect obedience requires that individuals renounce to their own will. The second part of the article focuses on Foucault's analysis of Saint Augustine's theory of libido, which shows that the condition of obedience, in particular the obedience to the sexual rules, relies on the good use that individuals make of their own will. The conclusions of the article highlight the crucial role of the interplay between obedience and will to understand the form of governmentality built up by the Christian experience of the Flesh.

Keywords: Michel Foucault. The Confessions of the Flesh. Flesh. Obedience. Will.

\section{A carne nas pesquisas sobre a História da sexualidade}

Propor uma análise focada sobre a obediência da carne nas últimas pesquisas de Foucault consagradas à História da sexualidade exige, ao menos, uma certa precisão conceitual. O que Foucault entende por carne? De qual maneira o filósofo se aproxima de um termo que já é extremamente complexo no próprio interior da literatura cristã? Se o corpus das últimas pesquisas foucaultianas sobre a História da sexualidade parece desenhar algumas linhas de força gerais para responder a esta questão, as dificuldades que esta suscita são, no entanto, consideráveis.

Como as primeiras páginas de O uso dos prazeres o sublinham, para Foucault (1984a) a carne é particularmente relevante enquanto uma "experiência". No quadro das "modificações" introduzidas pelo segundo volume de História da sexualidade, O uso dos prazeres, o termo "experiência" está no centro de um movimento por meio do qual Foucault propõe uma leitura retrospectiva e geral de suas próprias pesquisas, ao mesmo tempo em que precisa a perspectiva de seu empreendimento filosófico contrastando-a com a de outros tipos de "histórias", especialmente com aquela do "comportamento" e com aquela das 
"representações". Neste sentido, o projeto foucaultiano de uma história da sexualidade visa abordar a maneira como se constitui uma "experiência" na qual os indivíduos das sociedades ocidentais tiveram de se reconhecer como sujeitos de uma "sexualidade" que introduz, em particular, "domínios de conhecimentos muito diversos e que se articulam sobre um sistema de regras de constrangimentos". Ao longo das "modificações" de O uso dos pražeres, Foucault se apoia sobre o termo "experiência" a fim de articular os grandes traços ou dimensões de suas pesquisas e de poder assim afirmar que seu projeto "foi, então, uma história da sexualidade como experiência, — se entendemos por experiência a correlação, em uma cultura, entre domínios de saber, tipos de normatividade e formas de subjetividade". Foucault redefiniu assim as grandes questões de seu empreendimento consagrado ao estudo da sexualidade adaptando-o às precisões temáticas e de método que ele forja, especialmente em seus últimos cursos no Collège de France. De fato, nestes cursos esses três domínios são concebidos enquanto "focos de experiência" que se articulam entre si a fim de permitir a análise disto que Foucault entende por "pensamento" (FOUCAULT, 2008), ou como três "elementos" dos quais a relação permite estudar a parresia (FOUCAULT, 2009). A experiência enquanto conceito implica assim uma articulação com três termos dos quais os domínios são sempre os mesmos, mas cujo conteúdo é sempre histórico e específico. O conceito de experiência é composto, então, de uma parte estática ou "objetiva” (HAN, 1998) — sua armadura com três termos — e de uma parte dinâmica - o conteúdo sempre contingente que determina estes termos em um momento determinado. É assim que Foucault (1984a) pode sublinhar de maneira geral que a experiência moderna da sexualidade se compõe de três eixos: "a formação dos saberes que se referem à ela [a sexualidade], os sistemas de poder que regram a prática e as formas nas quais os indivíduos podem e devem se reconhecer como sujeitos desta sexualidade" (p. 11).

Ora, a experiência da sexualidade não é a única experiência considerada por Foucault no quadro de suas próprias pesquisas e hipóteses de trabalho. Com efeito, como sublinha reiteradas vezes $O$ uso dos prazeres, as últimas pesquisas de Foucault se apoiam sobre um grande esquema cronológico centrado sobre três experiências: a experiência antiga das aphrodisia, a experiência cristã da carne e a experiência moderna da sexualidade. No que 
concerne à experiência da carne, nas primeiras páginas do livro ela é evocada a fim de avançar uma hipótese que visa interrogar a aceitação geral da teoria, ou do tema teórico do "sujeito do desejo" ou "sujeito desejante" na abordagem moderna da sexualidade. Assim, Foucault afirma (1984a) que a experiência da sexualidade comporta uma figura histórica singular diferente da experiência cristã da carne, mas que "elas parecem ambas dominadas pelo princípio do homem de desejo" (p. 11). Esta hipótese justificaria a exigência de realizar uma "genealogia" do desejo e do sujeito desejante que permite explicar a formação e o desenvolvimento da experiência da sexualidade a partir do século XVIII, focando-se especialmente sobre a maneira pela qual "os indivíduos foram levados a exercer, sobre eles mesmos e sobre os outros, uma hermenêutica do desejo à qual o comportamento sexual desses indivíduos, sem dúvida, deu ocasião, sem, no entanto, constituir seu domínio exclusivo”(p. 12). No restante do livro consagrado à análise das aphrodisia, a experiência da carne é simplesmente mencionada, ou na maior parte dos casos, ela se esconde sobre os contrastes silenciosos que Foucault apresenta para melhor descrever as aphrodisia, reenviando assim a um jogo que somente o leitor especialista de Foucault ou do cristianismo poderia jogar.

A publicação de As confissões da carne (Les Aveux de la chair) permite preencher este vazio relativo ao conteúdo da experiência da carne, especialmente porque o livro lhe dá uma definição estrita. Esta definição se encontra no primeiro capítulo do agora quarto volume da História da sexualidade intitulado pelo editor "A formação de uma experiência nova":

A prática da penitência e dos exercícios da vida ascética organizam relações entre o "malfazer" e o "dizer verdadeiro", ela liga em feixes as relações a si, ao mal e ao verdadeiro, sobre um modo que é, sem dúvida, muito mais novo e muito mais determinante que este ou aquele grau de severidade adicionado ou deduzido do código. Trata-se, com efeito, da forma da subjetividade: exercício de si sobre si, conhecimento de si para si, constituição de si mesmo como objeto de investigação e de discurso, liberação, purificação de si mesmo e salvação através de operações que portam a luz até o fundo de si, e conduzem os mais profundos segredos até à luz da manifestação redentora. É uma forma de experiência - entendida simultaneamente como modo de presença a si e esquema de transformação de si - que então se elaborou. E é ela que colocou pouco a pouco ao centro de seu dispositivo o problema da "carne" [...] A "carne" tem um significado como um modo de experiência, ou seja, como um modo de conhecimento e de transformação de si por si, em função de uma certa relação entre anulação do mal e manifestação da verdade (FOUCAULT, pp. 50-51, 2018). 
Sendo assim, a carne aparece diretamente referida à noção de experiência e ligada em particular à dimensão da subjetividade. Como se sabe, a dimensão da subjetividade se encontra justamente no centro das últimas pesquisas de Foucault (1984a), especialmente daquelas consagradas à Antiguidade, sendo, aliás, a centralização das pesquisas sobre a questão da subjetividade aquilo que levou Foucault a focar na "história do homem do desejo" e na lenta formação de uma "hermenêutica de si" durante a Antiguidade. Ora, as relações entre a noção, por assim dizer, "estrita" da experiência da carne que encontramos em $A$ s confissões da carne e a definição de "experiência" que atravessa a "Introdução" de $O$ uso dos prazeres é complexa, especialmente por causa de duas razões. De uma parte, por causa da cronologia de duas obras e do próprio trabalho em curso de Foucault. Como sublinhamos anteriormente, a definição de experiência proposta por $O$ uso dos praz̧eres é certamente inspirada nas pesquisas de Foucault no Collège de France nos anos 1983-1984. Isto quer dizer que esta definição é posterior àquela da experiência da carne que encontramos doravante em As confissões da carne, da qual a redação definitiva é datada, como o observa Frédéric Gros (FOUCAULT, 2018), nos anos 1981-1982. Esta defasagem entre a escrita e a publicação de As confissões da carne exige uma certa prudência a respeito da maneira de interrogar a definição da experiência da carne que o livro propõe. Em particular porque no momento em que esta foi forjada, a definição de experiência que encontramos a partir de 1983, com sua armadura tripartite, não havia sido, provavelmente, articulada. De outra parte, a esta defasagem relativa ao trabalho em curso de Foucault, adiciona-se uma outra defasagem de conteúdo que concerne aos principais elementos que definem a morfologia da experiência da carne. Com efeito, como aponta a passagem de As confissões da carne que citamos acima, a experiência da carne seria organizada sobretudo a partir da prática da penitência e da vida ascética. Em termos mais precisos, estes dois momentos são relacionados a duas referências específicas, evocadas algumas linhas antes da passagem citada de As confissões da carne, a saber "a disciplina penitencial, a partir da segunda metade do segundo século e a ascese monástica a partir do final do terceiro" (FOUCAULT, p. 50, 2018). No corpo do livro, a análise da disciplina penitencial envolve especialmente o estudo da disciplina do batismo em Tertuliano; já a ascese monástica faz referência às análises que Foucault consagra aos textos de João 
Cassiano. Esta definição da experiência da carne focada sobre a disciplina da penitência e da ascese monástica contrasta, sem dúvida, com aquela evocada por O uso dos prazeres da qual o principal elemento seria “o princípio do homem de desejo". Isto porque, como se vê nas análises de Foucault, em nenhum destes dois elementos o desejo é problematizado como um objeto proeminente de reflexão. Dito de outra maneira, na definição da experiência da carne baseada em Tertuliano e Cassiano, que encontramos em As confissões da carne, o desejo não é um dos objetos em torno do qual se organiza esta experiência. Este contraste é ainda mais surpreendente se observamos que o último capítulo de As confissões da carne é consagrado à problematização da libido em Agostinho, no qual o problema do desejo do homem constitui a pedra de toque para compreender a ética sexual do casamento.

Não saberíamos explicar por que em As confissões da carne Foucault não inclui a problematização agostiniana da concupiscência como um dos elementos formadores da experiência da carne. Provavelmente esta exclusão de Agostinho é devida ao próprio work in progress [trabalho em andamento] do livro ${ }^{1}$. O fato é que se impõe a constatação de um deslocamento na conceitualização desta experiência: da redação de As confissões da carne para aquela de $O$ uso dos prazeres, a problematização do desejo por Agostinho adquire para Foucault um lugar fundamental como um dos elementos que dão forma e compõem a experiência da carne. Mais precisamente, este deslocamento, como o sugere a fórmula "hermenêutica do desejo" evocada numerosas vezes em O uso dos praz̧eres, parece propor uma nova articulação entre Cassiano ${ }^{2}$ e Agostinho como as duas referências principais em torno das quais gira a formação da experiência da carne.

\footnotetext{
${ }^{1}$ Para uma análise detalhada de este problema, consultar o nossos Colombo, A. "L'expérience des Pères: Les Aveux de la chair de Michel Foucault et la formation de l'expérience de la chair", Revue théologique de Louvain (no prelo).

${ }^{2}$ Como mostram as últimas pesquisas de Foucault sobre o cristianismo e como veremos brevemente, João Cassiano teria forjado uma "hermenêutica de si" pela reelaboração de técnicas de existência da Antiguidade e de uma articulação entre o exame de consciência e a confissão. Para uma análise detalhada do problema da articulação entre Cassiano e Agostinho e, portanto, da hipótese da origem cristã do "homem de desejo" consultar o nosso Colombo, A. (2020) "Michel Foucault y el hombre de deseo: Las Confesiones de la carne y los límites de la Historia de la sexualidad", Revista Anales del Seminario de Historia de la Filosofía 37 (1), 123-135.
} 
Nas linhas que seguem, interrogaremos os dois momentos maiores que $A s$ confissöes da carne consagra à análise do problema da obediência. Estes dois momentos correspondem-se justamente com os dois autores cristãos mencionados precedentemente, a saber, João Cassiano e Agostinho. Tomando por base esta análise, tentaremos compreender como, apesar da complexidade relativa na elaboração da noção de experiência, a publicação de $A s$ confissões da carne fornece elementos capitais para abordar melhor as últimas hipóteses de Foucault sobre a experiência da carne no quadro da História da sexualidade, particularmente à respeito das dinâmicas de poder e governo que esta experiência organiza.

\section{A obediência da ascese monástica: entre a renúncia da própria vontade e a incapacidade de conduzir a si mesmo}

O estudo das técnicas monásticas em As confissões da carne - apoiado especialmente nos escritos de João Cassiano ${ }^{3}$ - reserva um lugar específico e um tratamento individual ao problema da obediência, mesmo que este se desenvolva no interior da análise da direção espiritual.

Efetivamente, Foucault desenvolve uma conceitualização da "regra da obediência" sobre a base de três elementos que ele nomeia a partir de três palavras latinas. Em primeiro lugar, a subditio que explica o caráter global da obediência, ou seja, o fato que o monge deve obedecer em tudo. Este aspecto da obediência monástica implica que nenhum aspecto da vida escapa à forma da obediência e que, por consequência, todas as ações do monge sejam feitas sob uma ordem. Dito de outra maneira, o monge deve ser conduzido em todas as suas condutas: "conduzido pela regra, conduzido pelos comandos do abade, pelas ordens de seu diretor, eventualmente mesmo pelas vontades de seus irmãos, pois, se é verdade que estas não emanam de um superior ou de um ancião, elas têm este privilégio de ser vontade de um outro (FOUCAULT, p. 122, 2018). Em segundo lugar, a patientia que explica a forma e o valor da obediência monástica enquanto nos ligamos à vontade do outro sem importar o

\footnotetext{
${ }^{3}$ Foucault concentra sua análise em as Confêrencias e nas Instituições (CASSIEN, 2008, 2009 e 2001). Rev. Filos., Aurora, Curitiba, v. 32, n. 55, p. 181-202, jan./abr. 2020
} 
conteúdo desta vontade. Com efeito, a patientia exprime a ideia que na obediência monástica a vontade daquele que obedece deve ser completamente dócil e transparente à vontade de outrem. Assim, o princípio da patientia faz "tudo aceitar disto que quer o diretor e tudo suportar dele", mesmo as ordens mais absurdas e o fato de obedecer sem o menor atraso (FOUCAULT, p. 123, 2018). Neste sentido, a patientia pode ser compreendida como uma "não-resistência a tudo isso que o outro quer e impõe" que faz do monge "um tipo de matéria inerte entre as mãos daquele que o dirige” (p. 124). Enfim, o bumilitas que serve a Foucault para caracterizar a obediência como um fim em si mesma e como um "estado" ou uma "estrutura geral e permanente da existência". Mais precisamente, a humilitas faz da obediência uma forma de relação a si que opera uma abertura sobre outrem, ao invés de constituir uma dobra sobre si mesmo na qual o sujeito se fecha sobre si selando assim uma relação de autonomia ou de domínio de si. Este caráter de "figura aberta" da obediência é a garantia da heteronomia, visto que "ela opera de modo que o sujeito dê prioridade aos outros sobre si mesmo" (p. 124). Assim — explica Foucault — na bumilitas, o indivíduo tem consciência de ser tão baixo que não somente “ele se reconhece inferior a qualquer um” — o que explica que ele prefere a vontade de outrem à sua — mas também que ele não concede à sua própria vontade "nenhuma legitimidade e nenhuma justificação em querer".

Estes três elementos, longe de fazer da obediência uma estrutura fixa, asseguram a sua dinâmica e a relação do indivíduo consigo mesmo e com outrem, colocando, notadamente, no centro desta dinâmica um elemento específico, que é a vontade:

Sob estes três aspectos a obediência constitui, então, um exercício da vontade sobre ela mesma e contra ela mesma. Querer aquilo que os outros querem, em virtude do privilégio intrínseco e formal que detém a vontade de outrem, porque ela vem de outrem: isto é a subditio. Querer não querer, querer não se opor nem resistir, querer que em nada a própria vontade seja obstáculo à vontade do outro: isto é a patientia. Não querer querer, renunciar à menor de suas vontades próprias: isto é a humilitas (FOUCAULT, p.125, 2018)

No jogo do governo de si e dos outros forjado pelo monaquismo, a obediência e a problematização dinâmica da vontade que ela exercita têm um papel capital. $O$ incessante trabalho de uma vontade que quer — dramática e paradoxalmente — se anular nela mesma 
torna possível a implementação própria da direção espiritual. Todavia, ela é mais que a simples condição de possibilidade de funcionamento da direção. De fato, a obediência constitui o seu resultado visado e a garantia de sua reprodução. Pois, se de uma parte a obediência é "a condição inicial para que a direção possa operar seu trabalho", "o instrumento essencial da ação do diretor”, e mesmo “a forma geral da relação entre este e o dirigido", ela é também "o resultado ao qual conduz a direção" que "coloca o dirigido em posição de aceitar indefinidamente, em lugar e em substituição da sua, uma vontade outra" (FOUCAULT, p. 125, 2018). Mas, de outra parte, a obediência é também a garantia de reprodução da direção, visto que, como aponta Foucault evocando diretamente Cassiano, somente pode ser chamado a comandar — no contexto do qual Foucault faz referência, comandar deve ser compreendido como sinônimo de dirigir — "aquele que aprendeu a obedecer, e adquiriu 'pela formação recebida dos antigos aquilo que ele deverá transmitir aos mais jovens"'. Essa dinâmica da obediência com três termos, a partir da qual se desenvolvem as relações da vontade com e contra ela mesma, marca, assim, a vida monástica e as formas de governo que a caracterizam. Ora, na caminhada para a perfeição que constitui a vida monástica, a humildade possui uma posição particular. De fato, Foucault constata que, nos textos de Cassiano, a humildade exerce um papel de meio pelo qual se opera a passagem de uma caminhada que é marcada inicialmente pelo sentimento negativo do “"temor a Deus', o medo de seus castigos, o temor de provocar sua cólera ofendendo-o", para a "caridade", entendida como "a possibilidade de agir "pelo amor do bem em si mesmo e pela alegria que a virtude proporciona"” (p. 126). Como elemento que opera a renúncia à toda vontade própria, a humildade conduz a aceitar a vontade do outro como princípio de toda ação, o que no caso da caridade se traduz como aceitação da vontade de Deus como princípio de toda ação. É assim que sobre a base da obediência — e desta posição particular da humildade — a direção monástica pode chegar ao seu objetivo, a saber, a renúncia da vontade.

Ora, todo esse trabalho da vontade sobre ela mesma, que funda a problematização da obediência no monaquismo e constitui o núcleo da dinâmica governamental forjada pela ascese monástica, se apoia sobre um outro conjunto de técnicas. Este é formado pelo exame permanente de si e a confissão perpétua, e não somente completa o quadro do ascetismo 
monástico endereçado por Foucault, mas constitui o substrato a partir do qual o monge pode chegar a "essa obediência perfeita e exaustiva" (FOUCAULT, p. 121, 2018). É, então, desta maneira que a análise da governamentalidade monástica se articula com o que Foucault entende por "aleturgia", isto é, "o conjunto de procedimentos possíveis pelos quais se traz à luz aquilo que é posto como verdadeiro em oposição ao falso, ao escondido, ao indizível, ao imprevisível, ao esquecido" e que, enquanto tal, é inelutavelmente ligado ao exercício do poder. Isso porque "não há exercício do poder sem algo como uma aleturgia” (FOUCAULT, p. 8, 2012a). No caso do monaquismo, esta aleturgia é indispensável para adquirir o estado de obediência: deve-se examinar a si mesmo e dizer a própria verdade a fim de melhor obedecer.

O exame de si tem como objeto a análise dos movimentos dos pensamentos ou a cogitatio, termo empregado por Cassiano na esteira da reflexão evagriana sobre os logismoi $i^{4}$ e que se traduz não como um simples pensamento, mas como "aquele que arrisca, na alma entregue à contemplação, trazer a cada instante a perturbação” (FOUCAULT, p. 135, 2018). O objetivo do exame é estabelecer um diagnóstico de verdade, fazendo a triagem dos pensamentos desenvolvidos ao longo de um fluxo permanente. No entanto, este diagnóstico de verdade não visa interrogar a verdade das ideias, ou a verdade disto que é pensado na ideia, mas se aquele que pensa a ideia se engana ou não. É por isto que o exame concerne, em primeiro lugar, "a origem da ideia" ou "a qualidade dos pensamentos", pois trata-se de evitar as ilusões relativas à proveniência das cogitationes para, enfim, determinar se nos enganamos ou não quando acolhemos certas ideias. Assim, o exame interroga a origem dos pensamentos, mas, na realidade, o diagnóstico final concerne a verdade do sujeito pensante: o monge obediente e bem dirigido não considera aquilo que é pensado nestas ideias, "mas o movimento do pensamento naquele que o pensa" (FOUCAULT, p. 138, 2018). Este trabalho de exame permanente sobre si é explicado mais em detalhe em As confissões da carne na ocasião da análise que Foucault reserva às técnicas de si virginais em Cassiano, especialmente na

\footnotetext{
${ }^{4}$ Para Evagrio do Ponto a practikè - o método que purifica a alma e permite o acceso à ciência espiritual - consiste principalmente na luta contra os pensamientos inspirados pelos demônios para progredir em direção à impasibilidade (apatheia) (ÉVAGRE LE PONTIQUE, 1971).
} 
articulação entre a pesquisa incessante da puritas cordis e o combate espiritual permanente contra as forças demoníacas.

Mas voltemos ao quadro da exploração geral da ascese monástica para observar como se articulam aleturgia e governo. Para tanto é preciso observar a maneira como Foucault compreende a obrigação de manifestar a verdade de si monástica, o que nos leva a considerar um aspecto fundamental da dinâmica governamental no monaquismo, pois ele completa a abordagem relativa ao movimento de renúncia da vontade sobre ela mesma.

Como destaca Foucault (2018), o ideal de perfeição, do qual a pesquisa permanente caracteriza a vida monástica, explica que o monge deve evitar a desmedida dos excessos, ou seja, a possibilidade de cair, de uma parte, no "relaxamento a respeito das tarefas da vida ascética" e, de outra, no "excesso de zelo que, por caminhos diferentes, conduz frequentemente aos mesmos efeitos que o relaxamento". Cassiano chama discretio a capacidade de se conduzir evitando estes excessos. Como bem observa Foucault, este termo se inscreve na longa tradição filosófica, visto que ele é o equivalente da palavra grega diakrisis que, de fato, o próprio Foucault (1984b) evocará analisando o exame das imagens em Epiteto. No entanto, a problematização da discretio operada por Cassiano imprime a esses termos uma "coloração particular", assim como uma certa "inflexão" que são, na realidade, verdadeiros cortes nas formas de conceber o modo da relação a si. "Coloração particular" porque "é mais contra o excesso do zelo do que contra a frouxidão" — especialmente em relação ao ascetismo — que a discretio é dirigida (FOUCAULT, 2018). Uma certa “inflexão" por força da qual, diferentemente da abordagem da discretio própria à filosofia antiga, o cristão não pode se servir do uso de sua própria razão para ter a medida na maneira de se conduzir. Isso porque para Cassiano, mas também para São Jerônimo — sinaliza Foucault —, “o princípio da medida não deverá vir do próprio homem”, o que implica que o monge deve necessariamente fazer apelo a um "ponto de apoio fora de sua própria consciência". Dito de outra maneira, na vida monástica "a heteronomia do homem é fundamental e não é jamais a ele mesmo que ele deve recorrer para definir as medidas de sua conduta" (FOUCAULT, p. 131, 2018). 
A ruptura com o pensamento antigo é considerável. Ela se mede em particular a partir da comparação com a sōphrosunē concebida, justamente, segundo a definição que Foucault (1984a) a confere citando a Ethique à Nicomaque, como aquilo que permite ao sujeito ter em sua conduta a "justa medida entre a insensibilidade e o excesso" sobre a base de uma escolha dos princípios de ações conforme à razão. Ora, além da distância que separa Aristóteles de Cassiano, cuja espessura deixa perceber as profundas modificações introduzidas pela problematização monástica da discretio, a análise desta problematização permite delimitar uma dinâmica do governo mais complexa no centro da qual a relação do indivíduo a si mesmo não comporta somente uma renúncia da própria vontade. De fato, a análise da problematização da discretio em Cassiano mostra que o indivíduo é impedido de se apoiar sobre ele mesmo para poder se conduzir. A forma da relação a si monástica é da ordem da renúncia da vontade, mas também da impossibilidade de se conduzir a si mesmo. Em Cassiano a razão desta impossibilidade é que desde a queda "o espírito do mal estabeleceu seu império sobre o homem", em particular porque esse guarda com a alma humana um parentesco "de origem e de semelhança" que explica que o diabo pode vir tomar lugar no corpo enfraquecido, assim como na alma enviando-a "sugestões, imagens, pensamentos, dos quais a origem é difícil de discernir" (FOUCAULT, p. 131, 2018). Assim, a discretio é, antes de tudo, "um trabalho do pensamento sobre ele mesmo que se esforça para escapar às ilusões e enganos que a atravessam" (FOUCAULT, p. 132, 2018). A impossibilidade de se governar se conjuga com uma exigência de verdade que, por causa do ser mesmo do sujeito, enquanto sujeito decaído, é inevitavelmente perdida.

A saída deste impasse somente é possível com o recurso ao exterior do indivíduo. Este recurso exterior é primeiro e fundamentalmente aquele da graça divina - tema que Foucault evoca pela primeira vez em As confissões da carne, pois ele não é considerado em outras análises sobre o monaquismo que o filósofo realiza em Do governo dos vivos, no curso à Universidade de Louvain Malfazer, dižer verdadeiro (FOUCAULT, 2012b) ou nas conferências que ele dá no Dartmouth College sobre A origem da hermenêtica de si (FOUCAULT, 2013). Com efeito, a discretio é um dom que não tem nada de terrestre ou de pequeno, "mas um 
muito elevado presente da graça divina" (FOUCAULT, 2018). Diuinae gratiae maximum praemium diria Cassiano (2008). Mas, além de ser graça, a discretio é também uma virtude que se aprende pelo acoplamento do exame e da confissão que tem lugar no quadro da direção. Dito de outra maneira, discernimento só pode ser concedido pela graça, mas o indivíduo deve se esforçar no trabalho ascético para aprender a virtude do discernimento mesmo se ascese - enquanto atividade humana - será sempre insuficiente. Como explica Columba Stewart (1998), para Cassiano a graça e a vontade humana se articulam e cooperam no caminho para a vida contemplativa. No âmbito do trabalho ascético, a confissão desempenha um papel central, pois ela será o mecanismo a partir da qual o diagnóstico e a manifestação da verdade de si se tornarão, enfim, possíveis porque permite estabelecer um diagnóstico de verdade relativo aos pensamentos de duas maneiras. De uma parte, sobre a base do trabalho do diretor ao qual se confia que, apoiado sobre sua experiência e sobre a graça concedida por Deus, poderá “ver o que escapa ao próprio sujeito e o dar conselhos e remédios". De outra parte, a partir da capacidade de triagem e da virtude de purificação que possui o simples fato de exteriorização verbal. Neste sentido, a confissão tem um poder de "operador de discriminação" que Foucault explica a partir de uma série de razões que ele encontra em Cassiano, como, por exemplo, aquela da vergonha, de acordo com a qual "se se prova o mal ao confessar um pensamento, se este se recusa a ser dito, se ele busca permanecer secreto, este é o sinal de que ele é mal" (FOUCAULT, p. 140, 2018). Esse último aspecto da confissão relativa à sua própria forma verbal faz com que essa seja concebida como algo que possui uma virtude, uma virtus confessionis, pois "a confissão tem uma forma operatória que the é própria: ela diz, ela mostra, ela expulsa, ela entrega" (FOUCAULT, p. 142, 2018). Mas, apesar dessa operatividade "aletúrgica" própria da confissão, esta não pode ser isolada das dinâmicas governamentais da ascese monástica. Isso porque o acoplamento exame-confissão - ou isto que Foucault, apoiado sobre Basílio, chama exagoreusis 5 - constitui uma parte fundamental dessa, aperfeiçoando em particular a obediência:

\footnotetext{
${ }^{5}$ Foucault remete a São Basílio, P.G., t 31, col. 985 [trad. I. Hausherr] e ao livro de I. Hausherr Direction spirituelle en Orient autrefois. Rome: Pont. Institutum Orientalium Studiorum, 1955, p.155 sq.

Rev. Filos., Aurora, Curitiba, v. 32, n. 55, p. 181-202, jan./abr. 2020
} 
Antes de tudo o exame-confissão é ligado em sua permanência ao dever, também permanente, de obediência. Se tudo disso que se passa na alma e até os seus mínimos movimentos [deve ser revelado ao outro], é para permitir uma obediência perfeita. Não mais do que o ato aparentemente mais indiferente, o pensamento mais fugidio não deve escapar ao poder do outro. E, em troca, a obediência exata em todas as coisas tem por objetivo impedir que a interioridade jamais se feche sobre ela mesma e que ela possa, condescendendo-se na sua autonomia, se deixar seduzir pelas potências enganadoras que a habitam. A forma geral da obediência e da obrigação permanente de exame-confissão caminham necessariamente lado a lado (FOUCAULT, p. 143-144, 2018).

\section{A desobediência do homem e a libidinização do sexo em Agostinho}

O último ponto da terceira parte de As confissões da carne, intitulado pelo editor "a libidinização do sexo", constitui a parte do livro na qual é possível identificar outra análise detalhada do problema da obediência, ou mais precisamente da desobediência, no cristianismo. A desobediência é, de fato, uma questão central em torno da qual se dá a análise da elaboração sofisticada da abordagem da libido que completa o estudo da ética do casamento em Agostinho.

Como demonstra Foucault ${ }^{6}$, depois de Agostinho a desobediência é a causa da formação da libido no primeiro homem e, ao mesmo tempo, a libido é a marca indelével no gênero humano desta desobediência. Seja na perspectiva que Agostinho desenvolve na Cidade de Deus, segundo a qual o sexo paradisíaco era dócil e razoável de uma maneira tal que poderíamos nos servir dele como nos servimos dos "dedos da mão", ou que se trate da posição mais nuançada que ele adota no Contra Juliano, no qual ele admite a existência de "movimentos carnais" antes da queda, a tese agostiniana permanece a mesma: na criação, as relações sexuais eram da ordem do voluntário. Em termos mais precisos, a relação sexual no paraíso não tinha a forma constrangedora da libido e, neste sentido, tratava-se de um ato do

\footnotetext{
${ }^{6}$ Foucault enfoca a sua análise no livro XVI de la Cidade de Deus. Saint AUGUSTIN, La Cité de Dieu in Fuvres de saint Augustin, Paris, Desclé de Brouwer et cie, Bibliothèque augustinienne, introduction générale et notes par G. Bardy, traduction par G. Combés, 1959.
} 
qual todos os elementos estavam colocados "sob o controle exato e sem falhas da vontade" (FOUCAULT, pp. 330-331, 2018).

A libido que domina o ato sexual depois da queda implica justamente a irrupção do involuntário no voluntário e, por consequência, sua emergência envolve uma "reformulação das relações de obediência e de domínio do sujeito consigo mesmo (entre soi et soi) que dependem delas" (FOUCAULT, 2018). Esta irrupção do involuntário no voluntário - que na perspectiva de Agostinho é ilustrada em particular com a imagem da ereção —, não é mais que o efeito da desobediência do homem em relação ao Criador. Dito de outra maneira, a introdução na própria vontade dos movimentos que o homem é doravante incapaz de dominar é uma consequência da desobediência humana. Neste sentido, Foucault mostra que Agostinho faz uma leitura do castigo divino sobre a base de um equilíbrio bastante coerente que toma sua própria medida na própria desobediência. Isso porque se Deus puniu o homem, Ele não o fez a partir de um ato de desmedida que condenaria aquele ao império de forças que o dominariam eternamente. Punindo-o, Deus quis que o castigo fosse exatamente ajustado "tanto à queda, quanto às forças do homem e à possibilidade da salvação" fazendo assim que ele consista na "reprodução no homem da desobediência que teria feito o homem contra Ele" (FOUCAULT, p. 334, 2018). Assim, a partir deste princípio da inoboedientia reciproca, as consequências da queda se increvem "no próprio sujeito" que será doravante atravessado por uma cisão que faz que sua própria vontade se divida, se volte contra si, escapando, então, "a isto que ela mesmo pode querer".

Como no caso de Cassiano, a relação da vontade consigo mesma desempenha um papel capital para compreender a forma que a problematização da obediência adquire em Agostinho, mesmo se, como sublinhamos, no caso deste último, esta problematização é mais centrada sobre a desobediência. Ora, em Agostinho esta relação da vontade com ela mesma coloca em jogo duas dimensões particulares que permitem justamente indicar a diferença das abordagens entre Agostinho e Cassiano sobre as relações entre obediência e vontade. A primeira das dimesões envolve uma conceitualização na qual a libido constitui o elemento que define o sujeito enquanto tal. Nesta medida, ela é, no sentido estrito, uma definição do 
sujeito. A segunda, em contrapartida, permite a articulação de um campo jurídico no interior do qual as relações sexuais serão permitidas no quadro do casamento.

No que concerne a primeira destas dimensões, a desobediência do primeiro homem com Deus causa uma modificação do homem, pois, afastando-se de Deus, o homem se afasta da instância que o criou. No entanto, esta mudança não se traduz como uma alteração do homem enquanto criação de Deus, mas como uma "degradação do ser que se tem dele, e que se faz sentir cada vez mais à medida que se abandona Ele para se deleitar em si mesmo" (FOUCAULT, p. 342, 2018). O abandono de Deus e o retorno do homem sobre ele mesmo não tem a força de anular ou de desfazer a criação divina, mas de conferir ao ser do homem um caráter diminuído:

\begin{abstract}
Afastando-se de Deus, e recusando obedecê-lo, o homem pensava tornar-se senhor de si mesmo: ele acreditava libertar seu ser. Ele não faz senão decair de um ser que só se sustenta pela vontade de Deus. A revolta ulterior do corpo é a consequência desta vontade que, querendo seu ser próprio, se afasta disto que a faz ser, faz ela cair quando busca subir, e a enfraquece quando ela crê ter o domínio de si. O involuntário da concupiscência não deve ser pensado como uma natureza opondo-se ao sujeito, ou fechando-o ou levando-o para baixo; não se trata do corpo liberto de todo controle e escapando da alma; trata-se antes de tudo do ser inferior, da falta de ser do sujeito cuja vontade se encontra a querer o contrário do que ela queria. Vontade voltada contra si, vontade dissociada, por uma falha de ser que ela quis ela mesma ao querer ser por si mesma. (FOUCAULT, pp. 342-343, 2018).
\end{abstract}

A linha que divide o voluntário do involuntário se localiza no próprio indivíduo. Neste sentido, na diferença sobre certos elementos que Foucault identifica em Cassiano, a problematização agostiniana da vontade não é da ordem de um engano de origem externa que explica que o homem deva velar constantemente diante das ameaças satânicas porque estas podem o induzir a fazer algo que na realidade ele não quer fazer. Em Agostinho, o jogo do voluntário e do involuntário não admite alteridade. Ele é de cima a baixo e definitivamente colocado no interior do sujeito, ou para o dizer com as palavras de Foucault (2018): o involuntário da concupiscência "é inscrito, devido à queda, na estrutura atual do sujeito".

A segunda dimensão constitui na realidade um efeito da teoria agostiniana da concupiscência, a saber a "juridificação" da conduta sexual dos cônjuges. Este aspecto da abordagem da concupiscência forjada por Agostinho envolve a elaboração de elementos que 
permitem pensar sob uma perspectiva jurídica "práticas, regras, prescrições e recomendações que teriam sobretudo sido refletidas até então nas formas da ascese espiritual e de técnicas de purificação da alma” (FOUCAULT, p. 351, 2018). Neste sentido, esta elaboração se explica em grande parte pela diferença entre o horizonte da reflexão de Cassiano - a ascese espiritual e as técnicas de purificação monásticas - e aquele de Agostinho - a vida sexual do casal. Esta exigência - à qual Agostinho responde fixando um quadro jurídico para as condutas - estabelece os limites no interior dos quais a vontade revoltada do homem deverá se exercer para praticar como se deve a atividade sexual própria ao casamento, permitindo, assim, estabelecer um princípio de imputação ${ }^{7}$ da atividade sexual do casal. Assim, como sublinha Foucault (2018), Agostinho empreende a tarefa de "pensar simultaneamente e em uma só forma o sujeito de desejo e o sujeito de direito", e ele o faz especialmente sobre a base da articulação de duas noções: o consensus e o usus.

A noção de consentimento (consensus) permite atribuir a responsabilidade concreta e específica ao indivíduo para a maneira pela qual ele se serve de sua própria vontade enquanto sujeito de concupiscência. Assim, ela torna possível e inteligível a imputabilidade do pecado. Para que haja pecado atribuível ao sujeito é preciso a intervenção de um outro elemento diferente da presença permanente e constitutiva da concupiscência. Este outro elemento é justamente o consentimento. Ele é, então, um "suplemento" em relação à concupiscência a partir do qual a vontade, enquanto ato livre, pode querer aquilo que ela quer "enquanto concupiscência" (FOUCAULT, 2018). Por outro lado, a noção de usus permite uma articulação com o consentimento sobre a base da qual os comportamentos sexuais podem ser codificados em função de seus usos, de fins que eles se dão, de circunstâncias que os modificam, etc. No que concerne especificamente os fins, a procriação e a evasão do pecado para outrem - i.e. outrem é tomado como um meio de evitar a concupiscência -

\footnotetext{
${ }^{7}$ Um dos principais argumentos de Foucault para atribuir a Agostinho o fato de ter forjado uma "juridificação" dos atos sexuais, baseia-se na elaboração de um princípio de imputação que permite definir em que condições é adjudicado ao sujeito o cometimento de um pecado. Neste sentido, é notável que Foucault não evoca a importância da reflexão que Tertuliano, como bom jurista, desenvolve sobre a imputação dos pecados (Tertuliano, pp. 27-38, 1984). Diante desse silêncio, parece que para Foucault, a originalidade de Agostinho reside em ter forjado uma abordagem jurídica do problema da libido, isto é, ter articulado o desejo ao código ético-sexual do casamento.
} 
constituem os dois fins reconhecidos como legítimos e servirão como parâmetro ou fio condutor "para perscrutar o desenrolar de atos sexuais entre cônjuges, e definir o que é permitido, proibido, sob quais condições, em quais ocasiões" (FOUCAULT, 2018).

A articulação fina entre a teoria da libido e o quadro de imputação que apresenta o jogo entre o consensus e o usus, ou seja, a problematização simultânea do sujeito de desejo e do sujeito de direito possui, segundo Foucault, uma posição seminal no objetivo de compreender uma série de desenvolvimentos que terão lugar na Idade Média. De fato, na análise da libidinização do sexo operada por Agostinho, Foucault identifica a "matriz teórica" de uma elaboração que inclui inúmeras regras, bem como uma casuística relativa aos direitos e aos deveres das relações conjugais. Em termos mais precisos, a partir do século XIII o cristianismo desenvolve "uma codificação muito precisa de momentos, de iniciativas, de convites, de aceitações, de recusas, de posições, de gestos, de carícias, eventualmente, o veremos, de palavras, que podem ter lugar nas relações sexuais" (FOUCAULT, p. 359, 2018).

\section{A vontade renunciada e revoltada como questão governamental da carne}

Como observamos no começo deste texto, a problematização da "experiência da carne" forjada por Foucault envolve um desenvolvimento conceitual que vai da redação de As confissões da carne até aquela de $O$ uso dos prazeres. Neste desenvolvimento, Foucault não somente parece precisar as linhas de força que dão forma à experiência da carne, mas traça também os contornos de uma nova abordagem da noção de experiência. Em termos mais precisos, naquilo que concerne às principais referências da formação e do conteúdo da experiência da carne, o deslocamento se situa entre uma definição focada na disciplina penitencial - especialmente desenvolvida por Tertuliano - e a ascese monástica - em particular aquela forjada por João Cassiano - até uma aproximação da experiência da carne que gira em torno da hermenêutica do homem de desejo. Quanto à evolução da noção de experiência, esta parece compreender um movimento segundo o qual a 
experiência é, primeiro, a instância que organiza de maneira rudimentar os diferentes aspectos nos quais está em jogo a constituição da subjetividade - definição que encontramos doravante em As confissões da carne - para uma definição mais específica segundo a qual a subjetividade é um eixo específico que se articula com dois outros eixos, a saber aquele da verdade e aquele do poder.

Estes deslocamentos suscitam uma certa dificuldade quanto à maneira de elaborar a análise do cristianismo proposta por Foucault em As confissões da carne. Isso porque nós não saberíamos identificar as dimensões analíticas que, na época em que o texto foi escrito, Foucault ainda não teria delimitado. Neste sentido, seria claramente inapropriado interrogar a forma e a dinâmica da experiência da carne tal qual ela é concebida em $A s$ confissões da carne sobre a base da noção de experiência proposta nas pesquisas posteriores de Foucault. Particularmente, a tarefa de encontrar a articulação entre os três eixos da experiência — saber, poder e subjetividade — em As confissões da carne comportará um gesto forçado.

Não obstante, as análises que compõem As confissões da carne permitem fazer uma leitura que dá uma inteligibilidade nova e mais completa da experiência da carne à luz da elaboração da noção de experiência que encontramos nas últimas pesquisas de Foucault. Particularmente, no que concerne este trabalho, a ênfase posta sobre a obediência permite identificar as dinâmicas importantes quanto às questões relativas à governamentalidade, ou seja ao poder, isto é, o segundo eixo da noção de experiência. Nestas dinâmicas governamentais, o cristianismo parece ter desenvolvido especialmente uma rica e complexa análise da vontade que ocupa um lugar elevado para compreender a economia do modo pelo qual o indivíduo se conduz.

De fato, de um lado a análise da obediência monástica assinala uma dinâmica de governo na qual a renúncia do indivíduo à sua própria vontade desempenha um papel crucial. A renúncia da própria vontade permite o funcionamento da direção espiritual, no âmbito da qual tem lugar a aprendizagem da virtude na luta contra Satã, bem como o conhecimento e a purificação de si. De outro lado, a teoria da concupiscência elaborada por Agostinho desenvolve uma perspectiva segundo a qual, a partir da queda, a vontade 
do indivíduo volta-se contra ela mesma. Sobre a base desta problematização da vontade revoltada ergue-se uma economia fina da ética sexual do casal. Certamente, as questões relativas à governamentalidade, que envolve esta problematização da vontade, são menos transparentes que aquelas que podemos identificar na análise da obediência monástica. De fato, esta vontade revoltada não garante uma heteronomia como aquela que caracteriza a direção monástica, o que é claramente compreensível, pois Agostinho desenvolve a problemática da vontade concupiscente no quadro do casamento e não a partir de uma reflexão sobre os exercícios espirituais monásticos. Além disso, a articulação entre o consensus e o usus implica primeiro um jogo que se desenrola na espessura da relação do indivíduo consigo mesmo. Deste ponto de vista, a dinâmica da libido envolve sobretudo a constituição da subjetividade, embora Foucault não identifique em Agostinho nenhuma "técnica" específica. No entanto, é possível constatar que a dimensão da governamentalidade se encontra implicada na análise agostiniana da libido, em particular a partir da juridificação da conduta sexual que apresenta o quadro de atos permitidos e proibidos e, com este, as condições para imputar o pecado ao casal. A condução de condutas, como questão própria e específica da governamentalidade, não se faz tanto em relação a outrem, mas se desenvolve pela adequação da conduta sexual do casal a um conjunto de prescrições que se articulam com o jogo estabelecido pela relação entre o consensus e o usus. Embora, como afirma Michel Senellart (2013), o monaquismo para Foucault constitua um verdadeiro laboratório de governamentalidade cristã, parece claro que a problematização da vontade implicada pela teoria da libido de Agostinho abre outra dimensão da reflexão cristã da governamentalidade.

Neste sentido, a experiência da carne parece ter forjado uma problematização inaudita da vontade, na qual os movimentos refletidos da vontade contra ela mesma constituem uma questão central para compreender as dinâmicas do governo que caracterizam esta experiência. 


\section{Referências}

CASSIEN, J. Conférences I et II. Introduction, traduction et notes par Dom E. Pichery, Paris, Cerf (Sources chrétiennes), 2008-2009.

CASSIEN, J. Institutions cénobitiques. Introduction, traduction et notes par J-C Guy. Paris : Cerf (Sources chrétiennes), 2001.

CHEVALLIER, P. Michel Foucault et le christianisme. Lyon : ENS Éditions, 2011.

COLOMBO, A. "L'expérience des Pères: Les Aveux de la chair de Michel Foucault et la formation de l'expérience de la chair", Revue théologique de Louvain (no prelo).

COLOMBO, A. "Michel Foucault y el hombre de deseo: Las Confesiones de la carne y los límites de la Historia de la sexualidad", Revista Anales del Seminario de Historia de la Filosofía, v. 37, n. 1, p. 123-135, 2020.

ÉVAGRE LE PONTIQUE. Traité pratique I. Introduction par A. et C. Guillaumont. Paris : Cerf (Sources chrétiennes), 1971.

FOUCAULT, M. Du gowvernement des vivants. Cours au Collège de France 1979-1980. Paris: Seuil/Gallimard, 2012a.FOUCAULT, M. Histoire de la sexualité 1. La volonté de savoir. Paris: Gallimard, 1976.

FOUCAULT, M. Histoire de la sexualité 2. L'Usage des plaisirs. Paris: Gallimard, 1984a.

FOUCAULT, M. Histoire de la sexualité 3. Le souci de soi. Paris: Gallimard, 1984b.

FOUCAULT, M. Histoire de la sexualité 4. Les aveux de la chair. Paris: Gallimard, 2018.

FOUCAULT, M. Le courage de la vérité. Cours au Collège de France 1984. Paris: Seuil/ Gallimard, 2009.

FOUCAULT, M. Le gouverment de soi et des autres. Cours au Collège de France 1982-1983. Paris: Seuil/Gallimard, 2008.

FOUCAULT, M. Mal faire, dire vrai. Fonctions de l'aveu en justice. Cours de Louvain de 1981. Louvain-la-neuve: Presses universitaires de Louvain/University of Chicago Press, 2012b.

FOUCAULT, M. L'origine de l'herméneutique de soi. Conférences prononcées à Dartmouth College, 1980. Édition établie par H-P Fruchaud et D. Lorenzini. Paris: Vrin, 2013.

HAN, B. L'ontologie manquée de Michel Foucault (Krisis). Grenoble : Éditions Jérôme Millon, 1998.

Saint AUGUSTIN. La Cité de Dieu. In : Euvres de saint Augustin. Introduction générale et notes par G. Bardy, traduction par G. Combés. Paris: Desclé de Brouwer et cie, Bibliothèque augustinienne, 1959. 
SENELLART, M. Le christianisme dans l'optique de la gouvernementalité: l'invention de l'obéissance. In : BOQUET, D. ; DUFAL, B. ; LABEY, P. Une histoire au présent: les historiens et Michel Foucault. Paris : CNRS Éditions (Alpha), 2013.

STEWART, C. Cassian the Monk. New York: Oxford University Press, 1998.

TERTULLIEN, La pénitence, introduction, texte critique, traduction et commentaire par C. MUNIER. Paris : Cerf (Sources chrétiennes), 1984.

RECEBIDO: 20/12/2019

APROVADO: 09/01/2020

RECEIVED: $12 / 20 / 2019$

APPROVED: 01/09/2020 